\title{
Scrapping the Healthy Kids Check: a lost opportunity
}

\author{
Maintaining child preventive health and developmental assessments will challenge \\ general practice from 1 November
}

n May, the federal government announced in the 2015-16 Budget that the Healthy Kids Check (HKC) Medicare items will be discontinued from 1 November 2015, ${ }^{1}$ citing underperformance, cost blowouts and duplication of state and territory programs.

The HKC was introduced into general practice in 2008, policy that reflected advances in neuroscience (eg, the evolution of brain architecture, critical time points for development and the benefits of early intervention) and significant health shifts towards prevention. Uptake of the health assessment was slow ( $16 \%$ of eligible children in its first year ${ }^{2}$ ) and beset by argument about a lack of evidence for some of its mandatory components ${ }^{3}$ and by scaremongering about labelling 3-year-olds with mental health diagnoses. ${ }^{4}$ In the ensuing negative debate, it was easy to forget major barriers to preventive health care before the HKC: sick child consultations, poor remuneration, lack of time, resources and training, ${ }^{5}$ and the ever-increasing demands of chronic disease management in an ageing population. Nevertheless, over the next 7 years, uptake of the HKC climbed to $50 \%{ }^{2}$ as practice nurses were upskilled and parents were incentivised by tax benefits. ${ }^{6}$ Our research with practitioners, 3 years after its introduction, indicated that in some circumstances, the HKC had acted as a catalyst for general practitioner and practice nurse (PN) role development, and in some cases promoted an entire practice shift towards preventive health care for young children. ${ }^{7}$ The important contribution made by PNs, in particular, has been overlooked by the government in its statement that GPs can continue to provide health assessments as part of Medicare-funded general GP attendance items, ${ }^{8}$ because PNs are excluded from those services.

The government also contends that no evidence had been provided to show that HKCs deliver superior benefits to children. The findings of an evaluation of the "expanded HKC", which underwent trialled in eight Medicare Locals in 2013, have not been made public, but one published study considered the outcomes from HKCs and found that a fifth of HKCs uncovered some sort of health or developmental problem, and between $3 \%$ and $11 \%$ of HKCs changed the health management of the children concerned. ${ }^{9}$ Despite lower than expected prevalence estimates for some childhood conditions reported in this study (eg, overweight and oral health problems), the findings

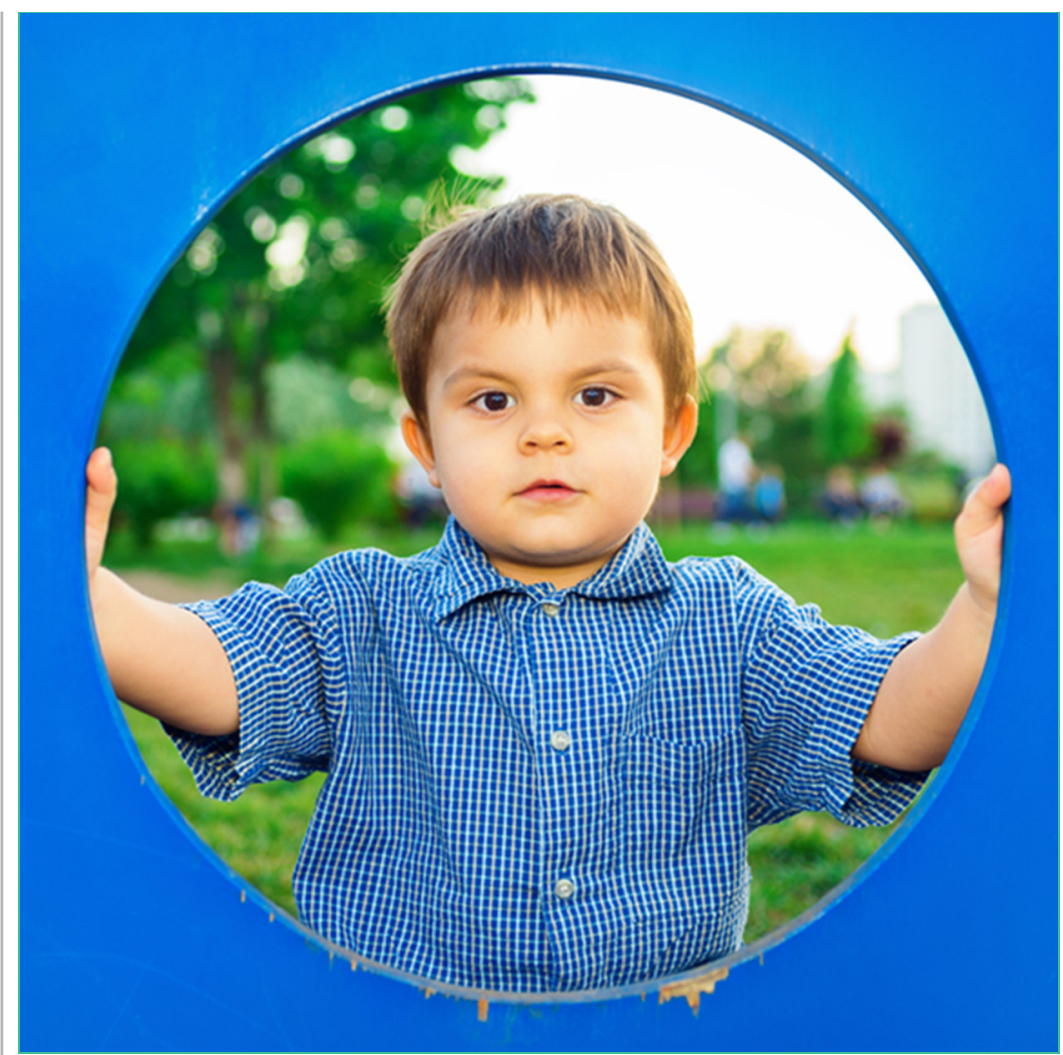

still showed that significant numbers of children could benefit from an HKC.

Duplication of state-funded child and family health nurse (CFHN) services was put forward as justification for the removal of HKCs. However, CFHN service delivery varies widely between the states. Even in Victoria, where comprehensive services are provided, only two-thirds of families attend the 3.5 year health assessment. ${ }^{10}$ Our research with parents revealed that although some parents were willing to visit CFHNs with their infants, not all parents presented with their toddlers. ${ }^{11}$ For a variety of reasons, parents "get busy", so that attendance rates drop off after the first year of a child's life and with successive children. ${ }^{11} \mathrm{We}$ do not know if CFHN non-attendees are the families receiving HKCs from the GP, but GPs are used to working with families and young children. Within this setting of established relationships, some parents choose to have their children vaccinated by their 
GP, rather than attend local council services or CFHN clinics. Providing parents with a choice of immunisation providers improves access and thus contributes to overall high coverage of child immunisation coverage.

Without a similar comprehensive approach to child developmental assessment, children will miss opportunities for early intervention. In 2012, for example, the average age of children being diagnosed with an autism spectrum disorder was 4 years 1 month despite diagnosis being possible in the second year. ${ }^{12}$ This suggests that many children are not being diagnosed before school.

The HKC also provides the context to address rates of childhood overweight that already affect more than $20 \%$ of preschoolers ${ }^{13}$ and rates of dental caries that affect one in two children aged 5 years. ${ }^{14}$ Without protected opportunities to engage parents regarding child preventive health and without the signal that the HKC gives to parents that GPs are interested in such issues, children will continue to miss out on preventive health activities routinely delivered to other sectors of the population.

\section{"we are effectively reducing the capacity of general practice to promote the health and development of young children, the most vulnerable in our population"}

By scrapping the HKC, not only are we reducing the chances of identifying problems earlier but we are effectively reducing the capacity of general practice to promote the health and development of young children, the most vulnerable in our population, who stand to gain the most over the course of their lifetime. This is a retrograde step for Australia's future.

Acknowledgements: This study was funded by the Shepherd Foundation, Melbourne, Victoria, and by a Chris Silagy Research Scholarship from the Royal Australian College of General Practitioners.

Podcast with Dr Karyn Alexander available at www.mja.com.au/ multimedia/podcasts and from iTunes. Also available as a video at www.mja. com.au/multimedia.
Competing interests: No relevant disclosures.

Provenance: Not commissioned; externally peer reviewed.

(c) 2015 AMPCo Pty Ltd. Produced with Elsevier B.V. All rights reserved.

References are available online at www.mja.com.au. 
1 Australian Government Department of Human Services. Budget 2015-16: Medicare Benefits Schedule - health assessment items - modification, 2015. http://www. humanservices.gov.au/corporate/publications-and-resources/ budget/1516/measures/health-matters-and-healthprofessionals/001784 (accessed Sep 2015).

2 Medicare Australia Statistics. Medicare items reports: Canberra: Australian Government Department of Human Services; 2015. http://medicarestatistics.humanservices.gov.au/statistics/mbs_ item.jsp (accessed Jul 2015).

3 Alexander KE, Mazza D. The Healthy Kids Check - is it evidence-based? Med J Aust 2010 Feb 15; 192(4): 207-10. https://www.mja.com.au/journal/2010/192/4/healthy-kidscheck-it-evidence-based

4 Frances A. Better safe than sorry. Aust N Z J Psychiatry 2012; 46: 695-696.

5 Waters EB, Haby MM, Wake M, Salmon LA. Public health and preventive healthcare in children: current practices of Victorian GPs and barriers to participation. Med J Aust 2000; 173: 68-71.

6 Australian Government Department of Human Services. Healthy start for school 2011. http://www.humanservices.gov. au/customer/enablers/centrelink/family-tax-benefit-part-apart-b/healthy-start-for-school-health-check (accessed Jul 2015).

7 Alexander KE, Brijnath B, Mazza D. Barriers and enablers to delivery of the Healthy Kids Check: an analysis informed by the Theoretical Domains Framework and COM-B model. Implement Sci 2014; 9: 60.

8 The Hon Sussan Ley MP. GPs still funded to deliver important kids checks 2015. https://www.health.gov.au/internet/
ministers/publishing.nsf/Content/health-mediarel-yr2015ley054.htm (accessed Jul 2015).

9 Thomas R, Doust JA, Vasan K, et al. Identified health concerns and changes in management resulting from the Healthy Kids Check in two Queensland practices. Med J Aust 2014; 201: 404-408. https://www.mja.com.au/journal/2014/201/7/ identified-health-concerns-and-changes-managementresulting-healthy-kids-check

10 Moore T. Best practice guidelines for parent involvement in monitoring and assessing young children. Melbourne: Department of Education and Early Childhood Development, 2008.

1 Alexander KE, Brijnath B, Mazza D. Parents' decision making and access to preventive healthcare for young children: applying Andersen's Model. Health Expect 2013. Epub 2013 Jun 25. doi:10.1111/hex.12100

12 Bent CA, Dissanayake C, Barbaro J. Mapping the diagnosis of autism spectrum disorders in children aged under 7 years in Australia, 2010-2012. The Med J Aust 2015; 202: 317-320. https://www.mja.com.au/journal/2015/202/6/mappingdiagnosis-autism-spectrum-disorders-children-aged-under-7years-australia

13 Wake M, Hardy P, Canterford L, et al. Overweight, obesity and girth of Australian preschoolers: prevalence and socioeconomic correlates. Int J Obes (Lond) 2007; 31: 1044-1051.

14 Chrisopoulos S, Harford JE. Oral health and dental care in Australia: key facts and figures 2012. Canberra: AlHW, 2013 (AlHW Cat. No. DEN 224.) http://www.aihw.gov.au/ publication-detail/?id=60129543390 (accessed Sep 2015). 